\title{
Ethical considerations of qualitative non-therapeutic research on people with obsessive-compulsive disorder: an overview
}

\section{[version 1; peer review: awaiting peer review]}

\author{
Abeer Ali A Hakami (DiD) 1,2 \\ ${ }^{1}$ English linguistics, Complutense University of Madrid, Madrid, Madrid, 28007, Spain \\ ${ }^{2}$ English language, Jazan University, Jazan, Saudi Arabia
}

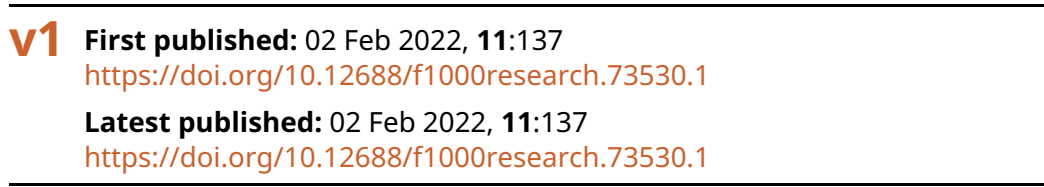

\section{Abstract}

Introduction: This paper discusses the ethical considerations involved in conducting qualitative non-therapeutic research on people suffering from obsessive-compulsive disorder (OCD), a topic covered in few, if any, prior studies.

Methods: The study summarizes in depth the existing literature on ethical aspects of conducting qualitative and nursing research with psychiatric patients. It constructs an overview of the most important points that should be taken into account when conducting nontherapeutic qualitative research on individuals with this disorder. Results: This paper draws attention to three ethical considerations: (1) informed consent; (2) OCD sufferer's competence to give consent; and (3) aspects of the relationship that arises between the researcher and participant.

Conclusions: This paper argues that those with OCD remain capable of giving consent, notwithstanding the continuing debates around their cognitive condition. It also provides an informative overview of aspects concerning their competence and insight, and suggests precautions to be followed when conducting interviews, paying attention to several factors that may determine the nature of the interview.

Keywords: qualitative research, non-therapeutic research, ethical considerations, obsessive-compulsive disorder.

\section{Keywords}

qualitative research, non-therapeutic research, ethical considerations, obsessive-compulsive disorder.

\section{Open Peer Review}

Approval Status AWAITING PEER REVIEW

Any reports and responses or comments on the article can be found at the end of the article. 
This article is included in the Research on

Research, Policy \& Culture gateway.

Corresponding author: Abeer Ali A Hakami (ahakamie@jazanu.edu.sa)

Author roles: Ali A Hakami A: Writing - Review \& Editing

Competing interests: No competing interests were disclosed.

Grant information: The author(s) declared that no grants were involved in supporting this work.

Copyright: $\odot 2022$ Ali A Hakami A. This is an open access article distributed under the terms of the Creative Commons Attribution License, which permits unrestricted use, distribution, and reproduction in any medium, provided the original work is properly cited.

How to cite this article: Ali A Hakami A. Ethical considerations of qualitative non-therapeutic research on people with obsessive-compulsive disorder: an overview [version 1; peer review: awaiting peer review] F1000Research 2022, 11:137 https://doi.org/10.12688/f1000research.73530.1

First published: 02 Feb 2022, 11:137 https://doi.org/10.12688/f1000research.73530.1 


\section{Introduction}

Obsessive-compulsive disorder (OCD) is a neuropsychiatric condition characterized by distressing repetitive thoughts and compulsive behavior (Lee \& Kwon, 2003). In recent years, qualitative non-therapeutic studies on OCD have increased in number; linguistic studies, especially. These linguistic studies revolve around the relationship of language to cognitive perception and the pathological factors that may affect linguistic production. Nevertheless, most of such studies tend to lack descriptions of the actual procedures of the recruitment processes in relation to trustworthiness and ethics (Carlsson et al., 2017). To elaborate, the stigma associated with intrusive and disturbing thoughts, some of which cannot be easily revealed due to the intensity of their exoticism, such as sexual or abusive thoughts, might make it difficult to collect a sample from persons with OCD. This raises questions about cultural and social factors that may limit the accessibility of the participants or the validity of the information extracted. In some qualitative linguistic research, these difficulties seem to lack any sufficient discussion and explanation ( $\mathrm{O}^{\prime} \mathrm{Neill}$, 1999; Knapton, 2016; Knapton, 2018; Ghahari et al., 2017). Although these studies have focused on examining various linguistic aspects and conceptual entities affected by the disorder, they failed to mention how the disclosure of obsessive thoughts may be directly affected by the social environment of the patient, and how these social factors may affect the participants and negatively worsen their condition. Additionally, they were not able to discuss how the OCD patients were made to feel safe and which methods were employed to get these individuals to participate in the studies in the first place.

Qualitative research allows individual experiences to become conspicuous and helps provide meaning for these experiences (Carlsson et al., 2017). Therefore, research regarding any mental illness requires consideration of the psychiatric patients' perspectives to establish a better understanding of the phenomenon being investigated. However, this approach has many challenges. A general idea seems to exist that people with mental illnesses are not able to make completely or partly autonomous decisions regarding their participation in a research study due to competence deficits. In fact, it has been found that the notion that psychotic patients are unable to make rational decisions has compromised the autonomy of all individuals with mental illness (Kane \& Schwartz, 1981; Usher \& Holmes, 1997). With this being said, OCD has been associated with neurobiological anomalies which differ from those found in other anxiety disorders (Radua et al., 2010). According to a wide body of evidence, patients with OCD have been shown to have neuro-cognitive disorders (Kuelz et al., 2004; Chamberlain et al., 2005; Muller \& Roberts, 2005; Menzies et al., 2008; Gonçalves et al., 2010; Melloni et al., 2012); thus, a vast range of tests exploring the characteristics of cognitive functioning in these individuals has been administrated in the past few decades (Flor-Henry et al., 1979; Behar et al., 1984; Head et al., 1989; Shin et al., 2014). The question that arises here is whether the supposed cognitive deficits of those with OCD should necessarily call for their special treatment and doubts regarding their autonomous ability to choose to participate in nontherapeutic qualitative research. In turn, this raises ethical concerns in the field of qualitative research involving the mentally ill and psychologically disturbed individuals, and challenges the role of health professionals as gatekeepers in the recruitment process and data collection in qualitative studies (Allbutt \& Masters, 2010).

The vigor of qualitative research on such a sensitive topic and vulnerable group needs scrutinizing in terms of the applicational methodologies related to trustworthiness and well-being of the participants. There are no studies, as far as the author is aware, regarding the ethical issues and considerations on conducting qualitative research involving individuals diagnosed with OCD despite the fact that mental health studies are expected to analyze and report all related matters of participant recruitment and data collection, including the phases of preparing, organizing, and reporting of the data (Elo et al., 2014), to attain trustworthy findings and outcomes (Carlsson et al., 2017). With this in mind, this paper aims to shed light on the ethical issues that involve psychiatric patients, particularly individuals with OCD, as participants in qualitative non-therapeutic research. The present study also aims to touch base with the technicalities that might enhance the credibility of the qualitative content analysis procedures via a discussion on the principles of informed consent and the cognitive and intellectual capacity of those with OCD to give consent, as well as a discussion on issues that arise in the relationship between researchers and participants.

\section{Methods}

The author is a linguist and is currently linguistically analyzing the narratives of OCD-affected individuals. However, the author found it significantly challenging to locate literature that explicitly addressed ethical considerations for nontherapeutic measures and sufferer competence. Thus, this study's ethical approach to non-therapeutic linguistics research was founded on readings related to ethical guidelines in medical psychiatry, especially in nursing research related to psychiatry. More specifically, the author borrowed from the following ethical guidelines outlined in various scientific journals specializing in the ethics of non-therapeutic scientific studies on people with mental and psychological disorders: (1) the relationship between a researcher who does not specialize in mental illnesses and the patient; (2) the cognitive abilities of patients with mental disorders; (3) and the patient's ability to independently decide to participate in nontherapeutic qualitative research. 


\section{Results and discussion}

\section{Informed consent and participants' competence}

Informed consent is a critical step when conducting research involving vulnerable individuals. In this process, an individual who is willing to participate in a research is well-informed and fully aware of all the procedures the research is intending to accomplish. In addition, there is a step that guarantees the dignity and autonomy of the participants. However, obtaining informed consent can be challenging at times due to factors involving culture, religion, interview locations, and the complexity of the research structure itself.

Unlike in quantitative research, it is almost impossible to fully inform the participants about the essence of the study at the beginning of any qualitative research due to frequent changes in the methodologies adopted (Ford \& Reutter, 1990). Therefore, the need for varied methods of data collection in any research project requires the careful consideration of ethical principles. Additionally, because ethics are subjective (Schwandt, 1994), participants need constant mediations and negotiations to participate in the research (Houghton et al., 2010), and a continuous reminder that they have the right to withdraw their participation at any time. This is a procedure called "process consent" (Munhall, 1988). Here, consent is a continuous process in which the participants remain aware of the potential benefits and risks of the research so that they are able to play a joint role in the decision-making process regarding their continued participation (Usher \& Arthur, 1998; Jokinen et al., 2002; Houghton et al., 2010). It is of huge importance that mentally ill and psychologically disturbed individuals maintain their dignity as autonomous persons when involved in any type of research; thus, the need for the informed consent process is evident for these individuals. In fact, one benefit of this process is the observed therapeutic effect that it brings to the psychiatric patients participating in the research: the mutual respect between the investigator and participant may enhance the patient's self-esteem and reduce feelings of incompetence (Brabbins et al., 1996).

With this being said, the actual application of some ethical procedure considerations throughout the process of ensuring an ethical study may sometimes be harmful for participating psychiatric patients. The unnecessarily overwhelming emphasis on the protection of the vulnerability of some psychiatric but non-psychotic patients, such as those with OCD, who may be competent enough to consent might unwittingly emphasize the stigma of mental illness, and further negatively affect their already damaged self-esteem (Usher \& Holmes, 1997).

In fact, the level of vulnerability may not be exclusively related to mental illness, as vulnerability in psychiatrics simply means the absence of a sound mind and the inability to make autonomous decisions (Usher \& Holmes, 1997). Research has shown that the claim that all psychiatric patients are vulnerable and thus are not able to fully provide consent was illfounded. A study by Kane \& Schwartz (1981) compared the abilities of hospitalized psychiatric and non-psychiatric patients to make a decision regarding exposing themselves to high-risk studies, and it found that psychiatric patients refused to participate in high-risk studies more often than non-psychiatric patients did. Hence, the level of psychopathology may not be a definite indicator of a patient's capacity to consent to research (Kane \& Schwartz, 1981). Therefore, under these circumstances, an essential question emerges: Do individuals with OCD meet the required competence levels to give consent to participate in a qualitative study?

Competence is a normative concept that does not necessarily define the patient's condition per se; rather, it gives the patient the power and eligibility to act upon a given task. When a patient is considered incompetent, he or she is not expected to meet the legal and ethical requirements for informed consent (Ruissen et al., 2012). Thus, competence is an essential pillar of valid informed consent and the lack of it raises many challenges. With this, competence in people with OCD has long been a slippery concept that lacks a straightforward answer.

The literature is filled with debate about the competence, cognitive abilities, and treatment decisional capacities of people with OCD. In fact, there are many studies that have explored several types of cognitive deficits and their locations in the brain of individuals with OCD (Boldrini et al., 2005; Shin et al., 2014; Kamaradova et al., 2016). However, there are almost no studies that clearly determine whether or not people with OCD are cognitively competent in a general sense, and what the ethical and legal consequences are for their participation in qualitative research for non-therapeutic purposes. For instance, Ruissen et al. (2015) explored the concept of competence from the perspectives of OCDaffected individuals and mental healthcare professionals regarding the patient's capacity to agree to receive appropriate treatment. From an OCD patient's perspective, competence involves recognizing and effectively navigating conflicting values and contradictory beliefs; that is, competence depends on the OCD-affected individual's ability to distinguish between normal and pathological behaviors related to general values in life as well as their ability to maintain balance in life. Specifically, while values like cleanliness, order, and perfectionism are not essentially pathological, OCD patients with compulsions associated with such values may struggle to recognize which related behaviors are normal or pathological. Conversely, from a mental health care professional's perspective, competence is conceptualized in cognitive terms, such as understanding, reasoning, appreciating, and expressing a choice, as well as the individual's 
inability to "live a good life" due to the burden of their disorder (Ruissen et al., 2015). However, these studies still do not answer the question of whether or not people with OCD are autonomously competent enough to make decisions unrelated to treatment (i.e., participating in non-therapeutic qualitative research).

The fact that people with mental disorders are always expected to have diminished cognition and intellectual impairments does not necessarily indicate their definite inability to consent (Koch et al., 1996; Amer, 2013). With psychiatric patients, competence to consent is similar to a person being able to consent to one task at a certain time but not to another (Usher \& Holmes, 1997). In addition, according to the MacArthur Competence Assessment Tool (MacCAT) (Grisso \& Appelbaum, 1998), four abbreviated elements of the term competence have been noted: (1) the ability of "expressing a choice", (2) the ability of "appreciation" of significant information beneficial to the patient's condition, (3) the ability of "reasoning" when making a decision, (4) and the ability of "understanding" relevant information (Ruissen, 2015).

Nevertheless, the MacCAT has been criticized for its cognitive bias (Grisso et al., 1995), with one controversial element being the patient's "appreciation". This is defined by Grisso and Appelbaum (1998) as the patient's ability to recognize and acknowledge the disorder, its main symptoms, and the benefits of treatment. However, this definition of "appreciation" has been challenged in that other non-authentic pathological values and ambiguity in identity, such as those found in anorexia nervosa disorder, might affect the competence more than the cognitive functions assessed by the MacCAT (Tan et al., 2010; Meynen \& Widdershoven, 2012; Ruissen et al., 2015). Therefore, it has been suggested that the definition of "appreciation" ought to be replaced with "the acceptance for the need for care" or "insight" (Tan et al., 2006). However, one more complicated issue emerges.

Competence and insight in OCD do not overlap, and the diagnosis of OCD as a non-psychotic disorder does not always necessarily mean that an OCD-affected individual is competent (Ruissen, 2015) as studies have shown that OCD-affected individuals with adequate insight can be incompetent, and the MacCAT may give false-positive outcomes. To demonstrate, according to the fifth edition of the Diagnostic and Statistical Manual of Mental Disorders (DSM-5), three subcategories of OCD are specified: (1) OCD with good or fair insight in which the individual is able to recognize that the obsessive-compulsive thoughts are not true; (2) OCD with poor insight wherein the individual thinks that the obsessive beliefs are probably true; and (3) OCD with absent insights or dysfunctional beliefs in which an individual is convinced that the obsessive thoughts are true (American Psychiatric Association, 2013). Nevertheless, due to the insufficient studies on individuals with OCD with poor insight, this group of patients is usually considered clinically competent without further assessment, which may lead to a poorer prognosis (Ruissen et al., 2012). Therefore, despite the fact that OCD is often associated with a generalized inability to make decisions (Sachdev \& Malhi, 2005; Rocha et al., 2011; Benzina et al., 2016) and impaired communication skills (Eisen et al., 2006; Ghahari et al., 2017), this paper argues that an individual with OCD is still capable of meeting the requirements of intellectual competence to consent to participating in a qualitative research study. As previously mentioned, this paper does not discuss the competence of a person with OCD to consent to medical treatment; rather, their ability to consent to participating in a qualitative non-therapeutic research.

Furthermore, one additional issue is the lack of awareness of the mental illness, which has been suggested to be a substantial indicator of the perceived incapacity in psychiatric patients (Grisso et al., 1995). However, this may not always be true in the case of OCD. Although a patient's life can be ravaged by the disorder, their cognitive functional competence is uniquely identified via a specific cognitive behavior; namely, the concealment of thoughts. To put it simply, people suffering from OCD attach catastrophic personal significance to their intrusive thoughts which may cause anxiety in these individuals (Newth \& Rachman, 2001). Regardless of the dysfunctional beliefs that are a feature of OCD (Belloch et al., 2006), only OCD sufferers with pure obsessions (Pure-O) who do not engage in compulsions (rituals) are aware of the silliness and irrationality of these thoughts, which leads to the eventual concealment of these thoughts to avoid accusations of craziness and misjudgments of their condition (Newth \& Rachman, 2001; Ruissen, 2015). This can be considered as an indication of insight that does not overlap with competence. The occurrence of the concealment phenomena in the early stages of treatment or when openness to others about the disorder is crucial for indicating that the person having these thoughts is indeed aware of their irrationality and they wish to stop them-regardless of whether or not they believe these thoughts to be true. Constant and tormenting doubts are also prevalent in OCD and is considered as one of the essential features of the disorder that force individuals with OCD to not only doubt their cognitive functions, but also their internal states such as comprehension, feelings, or beliefs (Boyer \& Liénard, 2006; Lazarov et al., 2012). Therefore, OCD-affected individuals may delay seeking professional treatment (Goodwin et al., 2002; Marques et al., 2010) because of the stigma, shame, and discrimination (Cathey \& Wetterneck, 2013). As a result, a person with OCD is expected to seek pathological behavioral rituals (e.g., repetition, checking, or avoidance) to ease the distress. Consequently, despite this deficit, people with OCD are able to function properly by using compensation strategies to help regulate their internal states (Shapiro, 1965; Reed, 1985). Thereupon, regardless of the pathological outcomes of seeking 
relief by attempting these aforementioned rituals, this suggests that they are cognitively capable and that problem solving skills are intact. Also, people with OCD have shown pragmatic competence via macrolinguistic competence indicators (i.e., discourse and pragmatic abilities), as claimed by Ghahari et al. (2017). These authors examined and compared the pragmatic production and recognition of OCD sufferers with non-sufferers. The study found that there were no significant lags of pragmatic recognition and production abilities observed between individuals with OCD and those without any psychiatric problems. Therefore, regardless of the cognitive and neural deficits in people with OCD (Okasha et al., 2000; Shin et al., 2014), and the overwhelming debate about the competence of these individuals to make their own treatment decisions, this paper argues that, until proven otherwise, individuals with OCD have a sufficient cognitive competence to preserve their right to their own independence and their ability to make decisions related to research participation.

\section{The relationship between the researcher and the participant}

Semi-structured interviews are considered the most favorable methods of conducting qualitative research. Since interviews require the communication between two or more individuals for the exchange of personal information and stories (Mishler, 1991), a sense of an intimate relationship might develop as the interview proceeds (Bulpitt \& Martin, 2010). Therefore, it is vital that researchers remain aware of the relationship that forms between the researcher and participant when conducting a qualitative non-therapeutic research on vulnerable individuals with sensitive conditions. This is further challenged by the fact that sensitive topics are often difficult to define (Dempsey et al., 2016), and are most often associated with emotions that evoke panic or dread (Lee, 1993). With that being said, it is of great significance to consider the potential effects of this inequality of power between the researcher and the vulnerable participant. Houghton et al. (2010) have mentioned three issues that might raise ethical challenges when conducting research studies on vulnerable people: (1) the way relationships are created and managed; (2) the imbalance of power between the researcher and the participant; and (3) the psychological, emotional, and personal effects that emerge as products of this relationship (Houghton et al., 2010).

To avoid any issues, an empathetic and reflexive approach to interviewing vulnerable participants and an attempt to understand the world from their perspective (Plas et al., 1996; Bulpitt, \& Martin, 2010) would ensure the participants' dignity and autonomy. In fact, researchers conducting reflexive research interviews have reported therapeutic benefits for the psychologically disturbed individuals who participate in this type of interview (Nicolson, 1995). One example is a case study by O'Neill (1999). Here, a sufferer narrates her story living with OCD. The researcher's analysis is then showed to the informant, who provides her comments on the analysis of her narratives in what is called "reflexivity within the research process." Since the participant was deliberately involved in the interpretation and analysis of her own narratives, this gave her the power to understand her thoughts and allowed her to reflect on her experiences to be better understood (O’Neill, 1999).

In a similar manner, it is of similar importance for qualitative researchers to be able to distinguish the fine line in which the interview might take a therapeutic direction when conducting non-therapeutic qualitative research. It is important to realize that a therapeutic environment might be naturally imposed on the interview due to the openness of the interviewee and the empathetic attitude of the researcher; hence, both therapeutic and intellectual interviews will eventually lead to understanding of and change of perspective on a given topic (Bulpitt \& Martin, 2010). The specific purposes of each one is clearly distinguished in that a therapeutic interview aims at personal change and is concerned with healing psychological distress, while a research interview targets intellectual understanding of the immediate benefit for both the interviewer and the interviewee (Plas et al., 1996; Bulpitt \& Martin, 2010). With this in mind, ethical considerations in terms of the benefits of interviewing vulnerable people on sensitive topics come to the fore. To clarify, Bulpitt and Martin (2010) argue that the roles of the interviewer and the interviewee in therapeutic and research interviews are significantly different, in terms of how the role of "helper" is uniquely recognized. In a therapeutic interview, the interviewer, the one who provides professional health care to ensure a stable mental health, is the helper for the interviewee. On the other hand, in a research interview, the interviewee is the helper who provides the necessary information to the interviewer to gain the utmost understanding of a given topic (Bulpitt \& Martin, 2010). Therefore, the overlap between the nature of interviews and the roles of the interviewing parties are crucial in establishing boundaries that prevent unethical manipulative actions between parties.

\section{Conclusion}

Ethical principles and considerations apply whenever scientific research is conducted on human participants, and this is especially true when dealing with vulnerable groups. Although the literature is saturated with the needed information on ethical guidelines and measurements, studies focusing on conducting qualitative research on people with OCD need further attention to uncover undiscovered aspects of scientific research in the lives of people with OCD. As this study has tried to show, the concept of competence in people with OCD is a significant factor that determines the validity of their informed consent, but there still remains a lack of a straightforward determination regarding the competence of these 
individuals. Also, interviewing people with OCD should not be arbitrary; rather, researchers must be aware of the impact that obsessive thoughts and images may have on the cognition of a sufferer, and hence act with careful and appropriate ethical considerations. Finally, it must be observed that this study is theoretical in nature, and that further studies on actual applicational aspects of qualitative non-therapeutic research should be conducted for more de facto findings. Also, this study suggests further research on OCD sufferers' competence in intellectual areas other than their capacity to make treatment decisions, as well as explorations of how interviews impact on their condition.

\section{Data availability}

No data are associated with this article.

\section{Author endorsement}

María-Ángeles Martínez Martínez confirms that the author has an appropriate level of expertise to conduct this research, and confirms that the submission is of an acceptable scientific standard. María-Ángeles Martínez Martínez declares they have no competing interests. Affiliation: Faculty of Humanities, University of Alcalá, Madrid, Spain.

Human/Animal Rights: The study did not have any animal or human subjects. Hence, all the necessary guidelines were a priority in the selection of other studies and in the creation of appropriate arguments.

\section{References}

Allbutt $\mathrm{H}$, Masters $\mathrm{H}$ : Ethnography and the ethics of undertaking research in different mental healthcare settings. J. Psychiatr. Ment. Health Nurs. 2010; 17(3): 210-215.

PubMed Abstract | Publisher Full Text

Amer AB: Informed consent in adult psychiatry. Oman Med. J. 2013; 28 (4): 228-231.

PubMed Abstract | Publisher Full Text

American Psychiatric Association: Diagnostic and statistical manual of mental disorders (DSM-5®).Arlington, VA: American Psychiatric Publishing; 2013.

Belloch A, Morillo Prats C, García-Soriano G: Obsession subtypes: relationships with obsessive-compulsive symptoms, dysfunctional beliefs and thought control strategies. 2006

Behar D, Rapoport JL, Berg CJ, et al.: Computerized tomography and neuropsychological test measures in adolescents with obsessive-compulsive disorder. Am.J. Psychiatry. 1984; 141(3): 363-369. PubMed Abstract | Publisher Full Text

Benzina $N$, Mallet $L$, Burguière $E$, et al.: Cognitive dysfunction in obsessive-compulsive disorder. Curr. Psychiatry Rep. 2016; 18(9): 1-11. Publisher Full Tex

Boldrini M, Del Pace L, Placidi GPA, et al.: Selective cognitive deficits in obsessive-compulsive disorder compared to panic disorder with agoraphobia. Acta Psychiatr. Scand. 2005; 111(2): 150-158.

PubMed Abstract |Publisher Full Text

Boyer $\mathrm{P}$, Liénard $\mathrm{P}$ : Why ritualized behavior? Precaution systems and action parsing in developmental, pathological and cultural rituals. Behav. Brain Sci. 2006; 29(6): 595-613.

PubMed Abstract | Publisher Full Text

Brabbins C, Butler J, Bentall R: Consent to neuroleptic medication for schizophrenia: Clinical, ethical and legal issues. Br. J. Psychiatry. 1996; 168(5): 540-544.

PubMed Abstract | Publisher Full Text

Bulpitt $\mathrm{H}$, Martin PJ: Who am I and what am I doing? Becoming a qualitative research interviewer. Nurse Res. 2010; 17(3): 7-16. PubMed Abstract | Publisher Full Text

Carlsson I-M, Blomqvist M, Jormfeldt H: Ethical and methodological issues in qualitative studies involving people with severe and persistent mental illness such as schizophrenia and other psychotic conditions: A critical review. Int. J. Qual. Stud. Health Well Being. 2017; 12 (sup2): 1-10.

Publisher Full Text

Cathey AJ, Wetterneck CT: Stigma and disclosure of intrusive thoughts about sexual themes. Journal of Obsessive-Compulsive and Related

Disorders. 2013; 2(4): 439-443.

Publisher Full Text
Chamberlain SR, Blackwell AD, Fineberg NA, et al.: The neuropsychology of obsessive compulsive disorder: the importance of failures in cognitive and behavioural inhibition as candidate endophenotypic markers. Neurosci. Biobehav. Rev. 2005; 29(3): 399-419.

PubMed Abstract | Publisher Full Text

Dempsey L, Dowling $M$, Larkin $P$, et al.: Sensitive interviewing in qualitative research. Res. Nurs. Health. 2016; 39(6): 480-490. Publisher Full Text

Eisen JL, Mancebo MA, Pinto A, et al.: Impact of obsessivecompulsive disorder on quality of life. Compr. Psychiatry. 2006; 47(4): 270-275

PubMed Abstract | Publisher Full Text

Elo S, Kääriäinen M, Kanste $O$, et al.: Qualitative content analysis:

A focus on trustworthiness. SAGE Open. 2014; 4(1):

215824401452263-215824401452210.

Publisher Full Text

Flor-Henry P, Yeudall LT, Koles Z], et al.: Neuropsychological and power spectral EEG investigations of the obsessive-compulsive syndrome. Biol. Psychiatry. 1979; 14(1): 119-130.

PubMed Abstract

Ford JS, Reutter LI: Ethical dilemmas associated with small samples. J. Adv. Nurs. 1990; 15(2): 187-191.

PubMed Abstract | Publisher Full Text

Ghahari S, Hassani H, Purmofrad M: Pragmatic competency and obsessive-compulsive disorder: A comparative assessment with normal controls. J. Psycholinguist. Res. 2017; 46(4): 863-875.

PubMed Abstract | Publisher Full Text

Gonçalves ÓF, Marques TR, Lori NF, et al.: Obsessive-compulsive disorder as a visual processing impairment. Med. Hypotheses. 2010;

74(1): 107-109.

Publisher Full Text

Goodwin R, Koenen KC, Hellman F, et al.: Helpseeking and access to mental health treatment for obsessive-compulsive disorder. Acto

Psychiatr. Scand. 2002; 106(2): 143-149.

PubMed Abstract | Publisher Full Text

Grisso T, Appelbaum PS: MacArthur competence assessment

tool for treatment (MacCAT-T). Sarasota, FL: Professional Resource

Press; 1998.

Grisso T, Appelbaum PS, Mulvey EP, et al.: The MacArthur treatment competence study II. Law Hum. Behav. 1995; 19(2): 127-148.

PubMed Abstract | Publisher Full Text

Head $D$, Bolton $D$, Hymas $\mathrm{N}$ : Deficit in cognitive shifting ability in patients with obsessive-compulsive disorder. Biol. Psychiatry. 1989; 25 (7): 929-937.

PubMed Abstract | Publisher Full Text 
Houghton CE, Casey D, Shaw D, et al.: Ethical challenges in qualitative research: Examples from practice. Nurse Res. 2010; 18(1): 15-25. PubMed Abstract | Publisher Full Text

Jokinen $\mathrm{P}$, Lappalainen $\mathrm{M}$, Meriläinen $\mathrm{P}$, et al.: Ethical issues in ethnographic nursing research with children and elderly people. Scand. J. Caring Sci. 2002; 16(2): 165-170.

PubMed Abstract | Publisher Full Text

Kamaradova D, Hajda M, Prasko J, et al.: Cognitive deficits in patients with obsessive-compulsive disorder-electroencephalography correlates. Neuropsychiatr. Dis. Treat. 2016; 12: 1119.

Publisher Full Text

Kane J, Schwartz N: Preliminary findings on psychiatric patients as research participants: A population at risk?. Am. J. Psychiatry. 1981; 138 (5): 669-671.

Knapton O: Dynamic conceptualizations of threat in obsessivecompulsive disorder (OCD). Lang. Cogn. 2016; 8(1): 1-31.

Publisher Full Text

Knapton O: The Linguistic Construction of the Self in Narratives of Obsessive-Compulsive Disorder. Qual. Res. Psychol. 2018; 1-23.Print. Koch HG, Reiter-Theil S, Helmchen H: Informed consent in psychiatry: European perspectives of ethics, law and clinical practice. Baden-Baden: Nomos Verl-Ges, Germany; 1st ed 1996.

Kuelz AK, Hohagen F, Voderholzer U: Neuropsychological performance in obsessive-compulsive disorder: a critical review. Biol. Psychol. 2004; 65(3): 185-236.

PubMed Abstract | Publisher Full Text

Lazarov A, Dar R, Liberman N, et al.: Obsessive-compulsive tendencies and undermined confidence are related to reliance on proxies for internal states in a false feedback paradigm. J. Behav. Ther. Exp. Psychiatry. 2012; 43(1): 556-564. PubMed Abstract | Publisher Full Text

Lee RM: Doing research on sensitive topics. Thousand Oaks, CA: Sage Publications; 1993.

Lee H-J, Kwon S-M: Two different types of obsession: autogenous obsessions and reactive obsessions. Behav. Res. Ther. 2003; 41(1): 11-29. Publisher Full Text

Marques L, LeBlanc NJ, Weingarden HM, et al.: Barriers to treatment and service utilization in an internet sample of individuals with obsessivecompulsive symptoms. Depress. Anxiety. 2010; 27(5): 470-475.

Publisher Full Text

Melloni M, Urbistondo C, Sedeño L, et al.: The extended fronto-striata model of obsessive compulsive disorder: convergence from eventrelated potentials, neuropsychology and neuroimaging. Front. Hum. Neurosci. 2012; 6: 259 .

Publisher Full Text

Menzies L, Chamberlain SR, Laird AR, et al.: Integrating evidence from neuroimaging and neuropsychological studies of obsessivecompulsive disorder: the orbitofronto-striatal model revisited. Neurosci. Biobehav. Rev. 2008; 32(3): 525-549.

PubMed Abstract | Publisher Full Text

Meynen G, Widdershoven G: Competence in health care: an abilitiesbased versus a pathology-based approach. Clinical Ethics. 2012; 7(1):39-44. Publisher Full Text

Mishler EG: Research Interviewing: Context and narrative. Cambridge, MA Harvard University Press; 1991.

Publisher Full Text

Muller J, Roberts JE: Memory and attention in obsessive-compulsive disorder: a review. J. Anxiety Disord. 2005; 19(1): 1-28.

Publisher Full Text

Munhall PL: Ethical considerations in qualitative research. West. J. Nurs. Res. 1988; 10(2): 150-162.

Publisher Full Text
Newth S, Rachman S: The concealment of obsessions. Behav. Res. Ther 2001; 39(4): 457-464.

PubMed Abstract | Publisher Full Text

Nicolson P: Qualitative research, psychology and mental health: Analysing subjectivity. J. Ment. Health. 1995; 4(4): 337-346.

Publisher Full Text

O'Neill SA: Living with obsessive-compulsive disorder: a case study of a woman's construction of self. Couns. Psychol. Q. 1999; 12(1): 73-86.

Okasha A, Rafaat M, Mahallawy N, et al.: Cognitive dysfunction in obsessive-compulsive disorder. Acta Psychiatr. Scand. 2000; 101(4): 281-285.

Publisher Full Text

Plas JM, Kvale S, Kvale SA: Interviews: An introduction to qualitative research interviewing. Thousand Oaks, CA: Sage Publications; 1996.

Radua J, van den Heuvel OA, Surguladze S, et al.: Meta-analytical comparison of voxel-based morphometry studies in obsessivecompulsive disorder vs other anxiety disorders. Arch. Gen. Psychiatry. 2010; 67(7): 701-711.

PubMed Abstract | Publisher Full Text

Reed GF: Obsessional experience and compulsive behavior: A cognitivestructural approach. London: Academic Press; 1985.

Rocha FFD, Alvarenga NB, Malloy-Diniz L, et al.: Decision-making impairment in obsessive-compulsive disorder as measured by the Iowa Gambling Task. Arq. Neuropsiquiatr. 2011; 69(4): 642-647.

Publisher Full Text

Ruissen A: Patient competence in obsessive-compulsive disorder: An empirical ethical study. 2015; 1-205.

Ruissen A, Widdershoven G, Abma T, et al.: Competence in obsessive compulsive disorder: The patients' perspective. Patient Competence in Obsessive-Compulsive Disorder. 2015; 83-107.

Ruissen A, Widdershoven G, Meynen G, et al.: A systematic review of the literature about competence and poor insight. Acta Psychiatr. Scand. 2012: 125(2): 103-113.

PubMed Abstract | Publisher Full Text

Sachdev PS, Malhi GS: Obsessive-compulsive behaviour: a disorder of decision-making. Australian \& New Zealand Journal of Psychiatry. 2005; 39 (9): 757-763.

Schwandt TA: Constructivist, interpretivist approaches to human inquiry. Handbook of Qualitative Research. 1994; 1: 118-137.

Shapiro D: Neurotic Styles. New York: Basic Books; 1965.

Shin NY, Lee TY, Kim E, et al.: Cognitive functioning in obsessivecompulsive disorder: a meta-analysis. Psychol. Med. 2014; 44(6): $1121-1130$

PubMed Abstract | Publisher Full Text

Tan JO, Hope T, Stewart A, et al.: Competence to make treatment decisions in anorexia nervosa: Thinking processes and values. Philosophy, Psychiatry, \& Psychology: PPP. 2006; 13 (4): 267-282.

Publisher Full Tex

Tan JO, Stewart A, Fitzpatrick R, et al:: Attitudes of patients with anorexia nervosa to compulsory treatment and coercion. Int. J. Law Psychiatry. 2010; 33(1): 13-19.

PubMed Abstract | Publisher Full Text

Usher KJ, Arthur D: Process consent: A model for enhancing informed consent in mental health nursing. J. Adv. Nurs. 1998 27(4): 692-697.

Publisher Full Text

Usher K, Holmes C: Ethical aspects of phenomenological research with mentally ill people. Nurs. Ethics. 1997; 4(1): 49-56.

Publisher Full Text 
The benefits of publishing with F1000Research:

- Your article is published within days, with no editorial bias

- You can publish traditional articles, null/negative results, case reports, data notes and more

- The peer review process is transparent and collaborative

- Your article is indexed in PubMed after passing peer review

- Dedicated customer support at every stage

For pre-submission enquiries, contact research@f1000.com 